\title{
Hexavalent molybdenum reduction to mo-blue by acinetobacter calcoaceticus
}

\begin{abstract}
A local molybdenum-reducing bacterium was isolated and tentatively identified as Acinetobacter calcoaceticus strain Dr.Y12 based on carbon utilization profiles using Biolog GN plates and 16S rDNA comparative analysis. Molybdate reduction was optimized under conditions of low dissolved oxygen ( 37 degrees $\mathrm{C}$ and $\mathrm{pH}$ 6.5). Of the electron donors tested, glucose, fructose, maltose and sucrose supported molybdate reduction after $1 \mathrm{~d}$ of incubation, glucose and fructose supporting the highest Mo-blue production. Optimum Mo-blue production was reached at $20 \mathrm{mmol} / \mathrm{L}$ molybdate and $5 \mathrm{mmol} / \mathrm{L}$ phosphate; increasing the phosphate concentrations inhibited the production. An increase in an overall absorption profiles, especially at peak maximum at $865 \mathrm{~nm}$ and the shoulder at $700 \mathrm{~nm}$, was observed in direct correlation with the increased in Mo-blue amounts. Metal ions, such as chromium, cadmium, copper, mercury and lead ( $2 \mathrm{mmol} / \mathrm{L}$ final concentration) caused approximately 88 , 53, 80, 100, and $20 \%$ inhibition, respectively. Respiratory inhibitors, such as antimycin A, rotenone, sodium azide and cyanide showed in this bacterium no inhibition of the Mo-blue production, suggesting that the electron transport system is not a site of molybdate reduction.
\end{abstract}

Keyword: Molybdenum reduction; Acinetobacter 